Provided for non-commercial research and education use. Not for reproduction, distribution or commercial use.

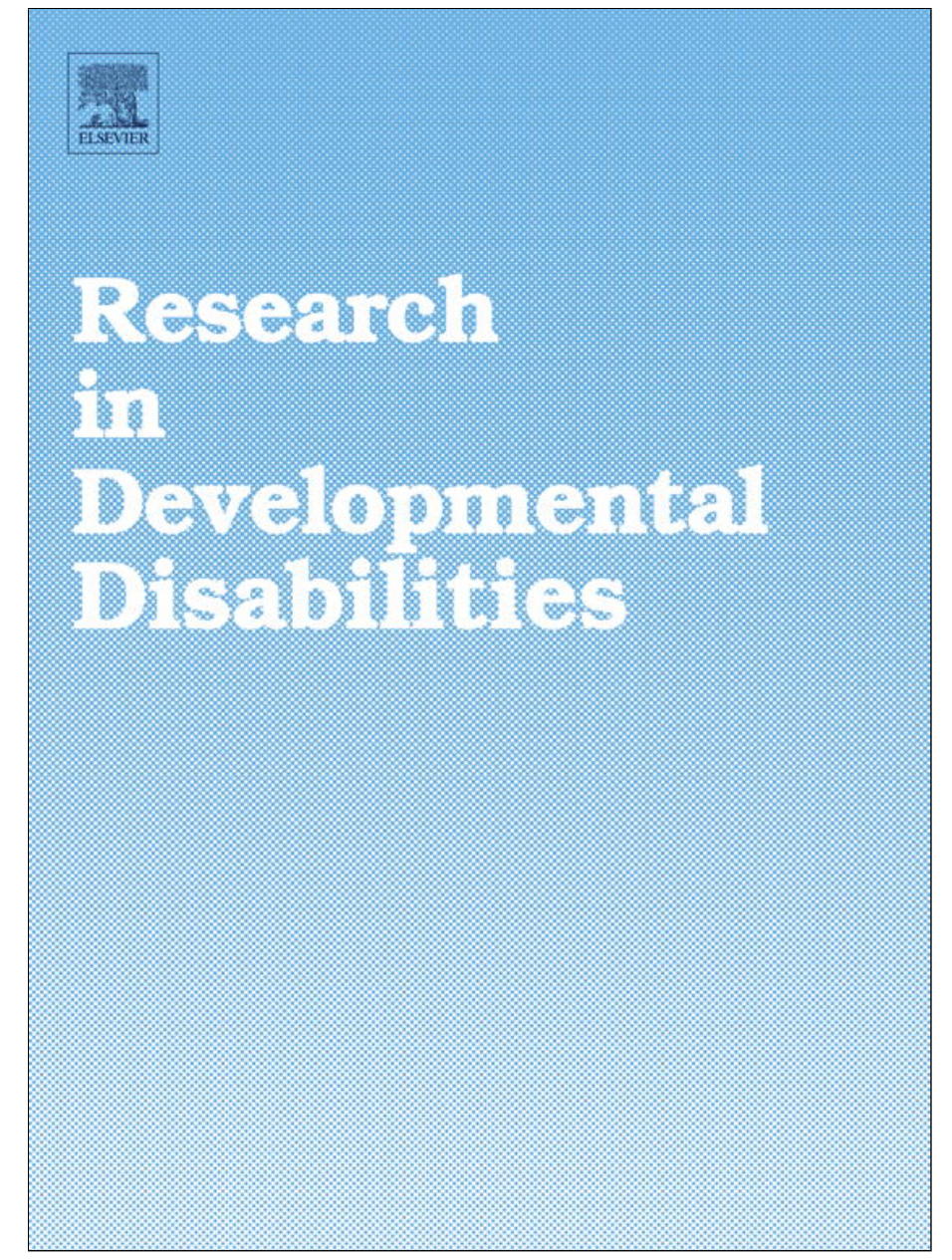

(This is a sample cover image for this issue. The actual cover is not yet available at this time.)

This article appeared in a journal published by Elsevier. The attached copy is furnished to the author for internal non-commercial research and education use, including for instruction at the authors institution and sharing with colleagues.

Other uses, including reproduction and distribution, or selling or licensing copies, or posting to personal, institutional or third party websites are prohibited.

In most cases authors are permitted to post their version of the article (e.g. in Word or Tex form) to their personal website or institutional repository. Authors requiring further information regarding Elsevier's archiving and manuscript policies are encouraged to visit:

http://www.elsevier.com/copyright 


\title{
Loneliness among students with special educational needs in mainstream seventh grade
}

\author{
Goele Bossaert $^{\mathrm{a}, *}$, Hilde Colpin ${ }^{\mathrm{b}}$, Sip Jan Pijl ${ }^{\mathrm{c}, \mathrm{d}}$, Katja Petry $^{\mathrm{a}}$ \\ ${ }^{a}$ Research Group Parenting and Special Education Research Unit, KU Leuven, Belgium \\ ${ }^{\mathrm{b}}$ Research Group School Psychology and Child and Adolescent Development, KU Leuven, Belgium \\ ${ }^{\mathrm{c}}$ Department of Special Education, University of Groningen, The Netherlands \\ ${ }^{\mathrm{d}}$ Department of Education, Norwegian University of Science and Technology, Norway
}

\section{A R T I C L E I N F O}

\section{Article history:}

Received 30 March 2012

Received in revised form 9 May 2012

Accepted 10 May 2012

Available online

\section{Keywords:}

Inclusive education

Special educational needs

Loneliness

Autism

Early adolescence

\begin{abstract}
A B S T R A C T
The goals of this study were twofold. The first aim was to explore loneliness prevalence in typically developing students, students with ASD and students with motor and/or sensory disabilities in mainstream 7th grade in Belgium. The second aim was to explore the relations between number of friends, friendship quality, social self-concept on the one hand and loneliness on the other for each of these three groups, and to compare them across groups. In this study, 108 students with special educational needs (SEN; i.e., 58 students with ASD and 50 students with motor and/or sensory disabilities) were matched to 108 typically developing classmates. Students with ASD reported more loneliness than typically developing students and students with motor and/or sensory disabilities. Loneliness prevalence for typically developing students and students with motor and/or sensory disabilities did not differ significantly. Factors related with loneliness differed between typically developing students and students with SEN (i.e., students with ASD and students with motor and/or sensory disabilities). For students with SEN, same-sex social self-concept was related with loneliness, but not, as for typically developing students, number of friends and opposite-sex social self-concept. Also friendship quality had a marginally significant effect on loneliness feelings for students with SEN. Implications for further research and practice are discussed.
\end{abstract}

(c) 2012 Elsevier Ltd. All rights reserved.

Over the last decades, worldwide educational policies concerning the education of students with special educational needs (SEN) have shifted in favor of inclusive education. In current literature, students with SEN are defined as "students with various (combinations of) difficulties in participating in education (Pijl, Frostad, \& Flem, 2008, p. 389)". As stated in Article 24 of the Convention on the Rights of Persons with a Disability of 2006, inclusive education aims to provide effective individualized support in environments "that maximize academic and social development, consistent with the goal of full inclusion" (United Nations, 2006). Belgium is one of the states that signed the Convention. In the federal state of Belgium, each community has its own education system (De Ro, 2008). Flanders, the Dutch-speaking region of Belgium, has long been known for its two-track education system (i.e., special and regular education system are two distinct systems; Meijer, 2003).

\footnotetext{
* Corresponding author at: Research Group Parenting \& Special Education Leopold Vanderkelenstraat 32, Box 3765, B-3000 Leuven, Belgium. Tel.: +32 16 373891; fax: +32 16325933 .

E-mail addresses: goele.bossaert@ppw.kuleuven.be, goele.bossaert@ped.kuleuven.be (G. Bossaert), hilde.colpin@ppw.kuleuven.be (H. Colpin), s.j.pijl@rug.nl (S.J. Pijl), katja.petry@ppw.kuleuven.be (K. Petry).
} 
Recently, a slow shift toward more inclusive education is noticeable. Currently, about $15 \%$ of all the students with SEN are fully included in Flemish mainstream schools (Watkins, 2010).

One of the leading motives of inclusive education is the social participation of students with SEN (Symes \& Humphrey, 2011). However, researchers disagree about the actual social participation of students with SEN in mainstream schools. Whereas some researchers sketch a positive social situation for students with SEN (Avramidis, 2010), others point to the risks (e.g., Frostad \& Pijl, 2007). One of these risks is loneliness. Loneliness is a subjective, unpleasant and distressing experience resulting from a discrepancy between the perceived quantity and quality of one's desired and one's actual relationships (Cassidy \& Asher, 1992; Peplau \& Perlman, 1982). High levels of loneliness among students with SEN in mainstream schools are a sign of low levels of social participation of students with SEN and imply that these students are socially at risk.

Loneliness among children seems to be widespread. A recent literature review showed that about 10-15\% of the children and adolescents felt very lonely (Galanaki \& Vassilopoulou, 2007). Based on studies among typically developing individuals, a peak in the prevalence of loneliness can be expected during adolescence (Perlman \& Landolt, 1999). During adolescence, the social expectations, roles, relationships, and personal identities of individuals undergo significant changes (Heinrich \& Gullone, 2006). Social relations become increasingly important and adolescents spend considerably more time with their peers, away from adult supervision (Brown \& Klute, 2003; Rubin, Bukowski, \& Parker, 2006). Additionally, early adolescence coincides with the transition from elementary to secondary school. In recent years, this transition phase, which is often marked by the breakup of old friendships and forming new relationships, has been highlighted as an area of concern (Hardy, Bukowski, \& Sippola, 2002; Humphrey \& Ainscow, 2006). These significant changes in adolescents' social worlds might be related to the peak in the prevalence of loneliness during this time.

It seems that students with SEN experience even more loneliness (e.g., Pijl, Skaalvik, \& Skaalvik, 2010; Reversi, Langher, Crisafulli, \& Ferri, 2007). One of the subgroups of students with SEN fully included in Flemish mainstream schools are students with autism spectrum disorder (ASD). Students with ASD form a special group when it comes to loneliness. For a long time, it has been suggested that children with ASD have a "basic desire for aloneness" (Kanner, 1943, p. 249). Aloneness is distinct from loneliness. Whereas aloneness is associated with a pleasant, positive and sometimes desirable situation, loneliness is not (Margalit, 1994). Only recently researchers have tried to solve the question whether students with ASD are satisfied with their aloneness, as suggested by Kanner, or if they do feel lonely. So far, several studies have indicated that children and adolescents with ASD indeed reported higher levels of loneliness in comparison to their typically developing peers (e.g., Bauminger \& Kasari, 2000; Bauminger, Shulman, \& Agam, 2003, 2004; Lasgaard, Nielsen, Eriksen, \& Goossens, 2010; Locke, Isjijima, Kasari, \& London, 2010; Whitehouse, Durkin, Jaquet, \& Ziatas, 2009).

Although these studies provide important insights into the experiences of individuals with ASD, a lot of questions remain unanswered. First of all, not much is known about loneliness prevalence of students with ASD during early adolescence. Former studies on loneliness of individual of ASD had very broad age ranges, with subjects between 8 and 17 years old. In only two studies, the grade/age range of the participants was limited to three grade levels (Chamberlain, Kasari, \& Rotherham-Fuller, 2007; Lasgaard et al., 2010) and one study did not report the grade/age ranges of the participants (Locke et al., 2010).

Secondly, although these studies give us a general idea about loneliness feelings among individuals with ASD, knowledge on loneliness among students with ASD in fully inclusive settings is still scarce. To date, the majority of the studies compared loneliness of students with ASD in special education or in self-contained classrooms in mainstream settings to loneliness feelings of typically developing students in mainstream education. Two studies have focused on loneliness among students with ASD in fully inclusive settings (i.e., Locke et al., 2010; Whitehouse et al., 2009). In the Whitehouse study (2009), students with ASD from three different provinces in Australia were compared to typically developing students from one particular school. In this study, students with ASD displayed higher levels of loneliness than the typically developing students. However, by comparing students of ASD with typically developing students from different schools, possible context-related factors could not be controlled for. Following the interactionist approach on loneliness, which considers loneliness as a result of the interaction between one's personal characteristics and their socio-cultural context, loneliness could differ across contexts (Heinrich \& Gullone, 2006). To rule out possible context-effects, it is important to compare loneliness rates of students within the same schools, and preferably within the same classes. Locke et al. (2010) has compared the loneliness prevalence of seven students with ASD with those of his/her typically developing classmates. Also in this study, students with ASD reported higher average loneliness rates than typically developing students.

Third, it is unclear if the loneliness rates of individuals with ASD differ from loneliness prevalence among other students with SEN. Currently, no comparisons in the loneliness rates of students with different types of SEN are available. Nonetheless, these comparisons are necessary to better understand if, and which, problems are unique to students with certain types of SEN (Chambers \& Kay, 1992; Whitehouse et al., 2009).

Fourth, although we do not have direct comparisons of loneliness rates of students with different types of SEN, we do have comparisons of loneliness rates of students with other types of SEN to rates of typically developing peers. The majority of these studies have focused on students with learning disabilities, whereas studies on loneliness among students with motor and/or sensory disabilities are rare (Pijl et al., 2010). Not much is known about loneliness prevalence among students with motor and/or sensory disabilities at the start of mainstream secondary education. The scarce studies among hard-of-hearing students or students with visual impairments report higher rates of loneliness compared to their typically developing peers (Huurre \& Aro, 1998; Kent, 2003; Most, 2007; Pijl et al., 2010). However this lack of knowledge on loneliness among students 
with motor and/or sensory disabilities in inclusive settings did not prevent the Flemish education system to include these students in mainstream schools. To date, students with motor and/or sensory disabilities constitute $45 \%$ of the students with SEN fully included in mainstream schools in Flanders (M. Vandekasteele, personal communication, March 12, 2012).

Besides lacks in knowledge on the prevalence of loneliness in different subgroups of students with SEN, current knowledge on the factors that might protect students with SEN against loneliness is limited as well (Lasgaard et al., 2010). These protective factors might be different in students with SEN compared to the typical population or even within subgroups of students with SEN. Based on the definition of loneliness as the result of a mismatch between the desire for, and the perception of the number and quality of a person's friendships, we can expect that number of friends and friendship quality are both related to feelings of loneliness. This seems to be confirmed in former studies among typically developing individuals and individuals with ASD. Nonetheless, these studies also suggest that the link between the number of friends, friendship quality and loneliness is less clear among individuals with ASD than among the typically developing population (e.g., Bauminger \& Kasari, 2000; Chamberlain et al., 2007; Whitehouse et al., 2009). Researchers mentioned several hypotheses to explain this lack of a clear link between aspects of friendships and loneliness. For example, students with ASD might have a different understanding of friendship and consequently nominated less positive and strong friendship relations than typically developing students, or that students with ASD have a degree of happy obliviousness, which might explain why social involvement cues do not affect them as much (Bauminger \& Kasari, 2000; Chamberlain et al., 2007; Whitehouse et al., 2009). So far, none of these hypotheses have been confirmed. Furthermore, low global and/or social self-esteem have been found to accompany high loneliness feelings in typically developing children and adolescents (Galanaki \& Vassilopoulou, 2007). So far, only one study assessed the relations between social self-concept and loneliness in individuals with ASD as well as in typically developing individuals (i.e., Bauminger et al., 2004). This study revealed a significant association between loneliness and social self-concept in both groups. However, none of the previous studies compared the protective influence of each of these factors against feelings of loneliness for students with ASD and typically developing students. Furthermore, it is not known whether protective factors all have the same effect against loneliness for students with different types of SEN.

This study aimed to answer some of these lacks in the current knowledge base on loneliness among students with SEN fully included in mainstream secondary education. In particular, the following research questions were investigated:

(1) Does the prevalence of loneliness differ among typically developing students, students with ASD, and students with motor and/or sensory disabilities?

(2a) Are there relations between number of perceived friends, friendship quality, social self-concept on the one hand and loneliness on the other for typically developing students, students with ASD, students with motor and/or sensory disabilities?

(2b) Do the relations between number of perceived friends, friendship quality and social self-concept on the one hand and loneliness on the other differ between these three groups, i.e., typically developing students, students with ASD, and students with motor and/or sensory disabilities?

Based on former research, we expected a higher prevalence of loneliness among students with SEN (i.e., students with ASD and students with motor and/or sensory disabilities) than among typically developing students. Moreover, we expected to find less strong negative relations of loneliness with number of perceived friends and friendship quality respectively among students with ASD than among typically developing students. On the other hand, we expected equally strong negative relations between social self-concept and loneliness among students with ASD and typically developing students. Because this is the first study which compares loneliness prevalence and the protective influence of number of perceived friends, friendship quality and social self-concept against feelings of loneliness among students with different types of SEN, no hypotheses were made regarding the differences in loneliness rates, or relations of number of friends, friendship quality, social self-concept and loneliness between students with ASD and students with motor and/or sensory disabilities.

\section{Method}

\subsection{Sample}

Participants for this study were 216 students (166 boys) in regular 7th grade classes, including 108 students with SEN. The group of students with SEN included 58 students with ASD (the ASD group) and 50 students with motor and/or sensory disabilities (the motor and/or sensory group). All students with SEN were fully included in 7th grade mainstream schools and eligible for extra support from a peripatetic teacher of a special education school. As the procedure prescribes, all students were assessed by a multidisciplinary team. From each school, we received information on the type of disability of their student(s) with SEN. This information was limited to the type of special education ${ }^{1}$ a student was entitled to and if the student(s) had a formal diagnose of ASD. To receive more detailed information, teachers were asked for extra information

\footnotetext{
1 The special education types in Flanders are based on the type of disability, i.e., motor disability, visual impairment, auditory impairment, but no separate special education type is allocated for students with ASD.
} 
regarding the type of disability. Information of both sources was combined, in order to correctly allocate the students to a certain group. None of these students had an intellectual disability. T-tests revealed that the ASD group and the motor and/or sensory group did not differ in age, socioeconomic status or ethnicity. As expected, there were more boys in the ASD group $(89.66 \%)$ than in the Motor and/or sensory group $\left(64.00 \% ; \chi^{2}(1)=10.23 ; p<.01\right)$. Current epidemiological data estimate the male to female ratio in autism to be 3-4:1 (Baird et al., 2006). In the normative IQ range, this ratio is even higher, as girls with autism, as a group, show higher rates of co-existing mental disabilities than males (e.g., Volkmar, Szatmari, \& Sparrow, 1993). Although some hereditary disorders are primarily found among boys (e.g., muscular dystrophy; Romitti et al., 2009), in general no such strong gender differences are found in other causes of motor and/or sensory disabilities.

In order to compare students with ASD and students with motor and/or sensory disabilities to their peers without SEN, classmates of the target students were recruited. For each child with SEN, the third classmate of the same gender on the alphabetically ordered name list was chosen. For two students with SEN, a classmate of a different gender had to be chosen, as there was no classmate of the same gender. This way, 108 typically developing students were selected (the Typical group). One-way ANOVAs and chi square tests revealed that students with ASD, students with motor and/or sensory disabilities and typically developing students did not differ significantly in age, socio-economic status nor ethnicity. However, they did differ in gender $\left(\chi^{2}(2)=10.04 ; p<.01\right)$, due to the higher proportion of boys in the ASD group than in the Motor and/or sensory group. However, after the Bonferroni correction, no significant differences in gender were found between students with ASD and students with motor and/or sensory disabilities on the one hand, and typically developing students on the other.

\subsection{Procedure}

Participants were identified at 54 schools, in 93 different 7th grade classrooms. Prior to identification of the participants, permission was obtained from the school principals. In a second step, an invitation letter for the parents of the students with SEN was sent to the school to hand out. Due to privacy reasons, parents or students were not contacted directly. Only after active consent was obtained from the parents of the students with SEN, separate consent forms were sent to the parents of the classmates, describing the research as a study of "friendships in schools". In the consent letter, children with SEN were not mentioned in the description of the study to assure participants' confidentiality. At the start of the questionnaire, students were asked for a written consent as well. The research project was approved by the Ethical Committee of research institution this research was carried out for. All questionnaires were administered online.

\subsection{Measures}

\subsubsection{Number of friends}

Sociometric nominations were used to assess the participants' number of friends within their class group. Based on a class list, students were asked to nominate their best friends in class. Students could nominate maximum five friends. Former similar studies (e.g., Pijl \& Frostad, 2010; Pijl et al., 2008) have indicated that five friends is a stable option, restricting the freedom of choice for respondents minimally. The number of friends a student nominated (i.e., outdegree) was used as an indicator of his/her number of friends.

\subsubsection{Friendship quality}

Friendship quality was assessed by an instrument developed by Malcolm, Jensen-Campbell, Rex-Lear, and Waldrip (2006) which assesses friendship quality of best friendships. Students were asked to answer four questions about the quality of the relation with each nominated friend. The items could be answered on a five point Likert scale ranging from strongly disagree (1) to strongly agree (5). The first question assessed companionship (i.e., 'I spend fun time with this person'; the second question tapped into intimacy/affection (i.e., 'I share private thoughts and feelings with this person'); the third and fourth question assessed support (i.e., 'I depend on this person for help, advice, and support' and 'This person sticks up for me'). Confirmatory factor analysis was applied to test if these questions could form a reliable scale. According to the cuttoff scores of $\mathrm{Hu}$ and Bentler (1999), ${ }^{2}$ confirmatory analyses revealed a good fit of the scale, i.e., $\chi^{2}(2)=0.25 ; \mathrm{RMSEA}=0.00$; CFI = 1.00; SRMR $<0.01$. Internal consistency of the items was very good, i.e., $\alpha=0.84$ (De Vellis, 2003). For each indicated friendship, the mean score on these four items reflected the quality of that nominated friendship. Finally, for each respondent, an overall quality measure was computed for all self-nominated friendships by averaging all quality scores of his/her self-nominated friendships.

\subsubsection{Social self-concept}

Students' social self-concept was assessed by means of two subscales (i.e., 'Same-Sex Relations', and 'Opposite-Sex Relations') of the Social Description Questionnaire II-Short (SDQII-S; Marsh, Ellis, Parada, Richards, \& Heubeck, 2005, Dutch

\footnotetext{
${ }^{2}$ According to Hu and Bentler (1999), a good fit is realized if the Satorra-Bentler-Scaled- $\chi^{2}$ statistic is as low as possible, Root-Mean-Square Error of Approximation (RMSEA) is less than .06, Comparative Fit Index (CFI) is equal to or higher than .95, and Standardized Root-Mean-Square Residual (SRMR) is equal to or lower than .08 .
} 
version by Simons \& Vangenechten, 2002). The SDQII-S is designed to measure multiple dimensions of self-concept, and is appropriate for use among students in Grades 7-12. The psychometric qualities of the SDQII-S are good (Marsh et al., 2005). The subscale 'Same-Sex Relations' includes five items, such as 'It is difficult to make friends with members of my own sex'. The subscale 'Opposite-Sex Relations' includes four items, such as 'I am not very popular with members of the opposite sex'. All items were rated on a six-point Likert scaling, ranging from $1=$ false to $6=$ true. Some of the items (including the examples) were reverse-coded, so that higher scores reflected higher levels of social self-concept. In our sample, internal consistency was respectable for the Same-Sex Relations subscale and acceptable for the Opposite-Sex Relations subscale (De Vellis, 2003; Same Sex Relations: boys: $\alpha=0.80$, girls: $\alpha=0.73$; Opposite-Sex Relations subscale: boys: $\alpha=0.73$, girls: $\alpha=0.64)$.

\subsubsection{Loneliness}

Loneliness among students with SEN and their classmates was assessed by means of the short version of the peer-related loneliness scale of the Loneliness and Aloneness Scale for Children and Adolescents (LACA; Marcoen, Goossens, \& Caes, 1987). The original LACA-Peers scale consists of 12 items, and is recommended for use to tap into loneliness in the peer context (Goossens et al., 2009). In this study, a short version of the LACA-Peers was used, consisting of six items, such as 'I am sad because I don't have any friends'. These six items had the best factor loadings in a norm group of 9455 Flemish children and adolescents (L. Goossens, personal communication, April 30, 2010). All items were rated on a 4-point Likert scale, ranging from never (1) to often (4). Higher scores indicate higher degrees of loneliness. In our sample, internal consistency of the short LACA-Peers subscale was very good (De Vellis, 2003; $\alpha=0.87$ ).

\subsection{Analysis}

ANOVAs were used to test for differences in loneliness prevalence between typically developing students, students with ASD and students with motor and/or sensory disabilities. Because the proportion of girls differed between the three groups (i.e., students with ASD, students with motor and/or sensory disabilities, and typically developing students), gender and the interaction effects with other independent variables were included as a control variable. To control the overall Type I error rate, the Bonferroni correction was used when performing post hoc analyses, comparing the groups one-to-one.

To examine the relation between number of friends in class, friendship quality, social self-concept on the one hand and loneliness on the other, one-tailed Spearman rho correlations were calculated for each group. In a second step, separate multiple regression analyses with loneliness as the criterion were carried out for each group (i.e., students with ASD, students with motor and/or sensory disabilities and typically developing students). The number of perceived friends in class, overall perceived friendship quality, same-sex social self-concept and opposite-sex social self-concept, were used as predictors. Gender was included as a control variable. Assumptions of the linear models were satisfactory. The proportion of values of the standardized residuals outside the range $(-2,+2)$ for three regression analyses were between $0 \%$ and $5 \%$. Nonetheless, three outliers $(3 / 48=6.25 \%)$ were found in the group of students with motor and/or sensory disabilities but Cook's distance stayed well below the critical value of 1 for all regression analyses (Field, 2009).

The results of these separate regression analyses for each group were compared one by one (Garbin, 2012). In a first step, differences in the fit of the separate regression analyses were tested by means of the Fisher $z$-test. In a second step, differences in the structure of the models were tested. Therefore, two $R^{2}$ values were compared to each other by means of the Steiger Z-test (Meng, Rosenthal, \& Rubin, 1992). The first $R^{2}$ is the $R^{2}$ of the model for the reference group (i.e., the largest group of the two) or the "direct $R^{2}$ ". The second $R^{2}$ is the $R^{2}$ generated by applying the model from the second group to the

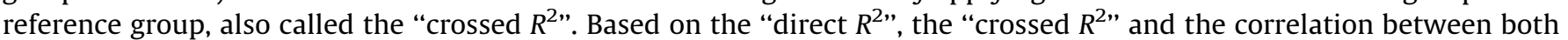
models, the Steiger $Z$ test can be calculated. In a third step, differences in the weights of individual predictors were compared between groups, by means of the formula proposed by Paternoster, Brame, Mazarolle, and Piquero (1998).

\section{Results}

\subsection{Group differences in feeling lonely}

Results of the scores on the loneliness scale for each subgroup are displayed in Table 1. For a more detailed picture of the findings, the percentage of students who score high on the loneliness scale was calculated. As no cut-off scores of the LACAPeers Short were available, Marcoen and Goossens (1990) recommended considering scores higher than one standard deviation, as high. For this sample, the mean score on the LACA-Peers Short was 10.66 with a standard deviation of 4.26 . Consequently, all scores higher than 14.92 were considered to be high. Based on the descriptive in Table 1, it seems that students with ASD are twice as often lonely than typically developing students $\left(31.03 \%\right.$ vs. $13.89 \%$; $\chi^{2}(1)=6.97$, after Bonferroni correction $=p<.05$ ) and 2.5 times more often lonely than students with motor and/or sensory disabilities (31.03\% vs. $12.00 \% ; \chi^{2}(1)=5.62$, after Bonferroni correction $\left.=p=.05\right)$.

Two-way independent ANOVAs revealed a significant difference in the frequency of loneliness of typically developing students, students with ASD and students with motor and/or sensory disabilities $(F(2)=6.86, p<.01)$. No significant differences in loneliness prevalence were found between boys and girls $(F(1)=0.19 ; p>.05)$ and no interaction effects between type of student and gender were found $(F(2)=1.15, p>.05)$. Post hoc analyses revealed that students with ASD 
Table 1

Differences in feelings of loneliness among typically developing students, students with ASD and students with motor and/or sensory disabilities.

\begin{tabular}{|c|c|c|c|c|c|c|}
\hline Group & $N$ & $M$ & $S D$ & Min & Max & \% High loneliness \\
\hline \multicolumn{7}{|c|}{ Typically developing students } \\
\hline Total & 108 & 9.80 & 4.22 & 6.00 & 24.00 & 13.89 \\
\hline Boys & 82 & 9.95 & 4.36 & 6.00 & 24.00 & 14.63 \\
\hline Girls & 26 & 9.31 & 3.79 & 6.00 & 19.00 & 11.54 \\
\hline \multicolumn{7}{|c|}{ Students with ASD } \\
\hline Total & 58 & 12.45 & 4.12 & 6.00 & 23.00 & 31.03 \\
\hline Boys & 52 & 12.21 & 3.90 & 6.00 & 20.00 & 28.85 \\
\hline Girls & 6 & 14.50 & 5.68 & 6.00 & 23.00 & 50.00 \\
\hline \multicolumn{7}{|c|}{ Students with motor and/or sensory disabilities } \\
\hline Total & 50 & 10.46 & 3.95 & 6.00 & 24.00 & 12.00 \\
\hline Boys & 32 & 10.69 & 4.19 & 6.00 & 24.00 & 12.50 \\
\hline Girls & 18 & 10.06 & 3.56 & 6.00 & 18.00 & 11.11 \\
\hline
\end{tabular}

reported higher feelings of loneliness than students with motor and/or sensory disabilities $(p<.05)$, and typically developing students $(p<.001)$. No significant difference in frequency of loneliness feelings emerged between students with motor and/ or sensory disabilities and typically developing students.

\subsection{Friendships, social self-concept and loneliness}

Preliminary analysis tested how many students per group did not indicate having a friend within the class. In the Typical group, only one student (1/108) indicated not having a friend, while in the ASD group four students (4/58) and in the Motor and/or sensory group two students (2/50) indicated not having a friend in the class. Consequently, for these students, no data on the quality of their friendships is available.

To examine the links among friendships, social self-concept and loneliness, one-tailed Spearman Rho correlations were calculated for each group. Results are displayed in Table 2.

For all groups, significant negative associations were found between loneliness on the one hand and same-sex social selfconcept and opposite-sex social self-concept on the other. In the Typical group and the Motor and/or sensory group, also significant negative associations were found between loneliness and friendship quality. Only in the Typical group, significant negative associations were found between loneliness on the one hand and number of friends on the other.

Multiple regression analyses found that same-sex and opposite-sex social self-concept predicted loneliness in the Typical group $\left(R^{2}=0.38, F(5,101)=12.16, p<.001\right)$. The effect of number of friends of typically developing students was marginally significant $(p<.10)$. For students with ASD and students with motor and/or sensory disabilities, only same-sex social selfconcept (and not opposite-sex social self-concept or number of friends) predicted loneliness (students with ASD: $R^{2}=0.48$, $F(5,48)=9.00, p<.001$; students with motor and/or sensory disabilities: $\left.R^{2}=0.40, F(5,42)=5.58, p<.001\right)$. Gender had a marginally significant effect on loneliness for students with ASD; with girls reporting higher levels of loneliness $(p<.10)$. For none of the groups, friendship quality had a significant effect on loneliness.

First, differences between the regression analyses of students with ASD and students with motor and/or sensory disabilities were tested. Comparison of the fit of the model from the ASD group and the Motor and/or sensory group revealed that there was no significant difference between the respective $R^{2}$ values $(Z=0.56, p>.05)$. Also the structure of the models

Table 2

Correlation and multiple regression weights for all groups of students.

\begin{tabular}{|c|c|c|c|c|c|c|c|c|c|c|c|c|}
\hline & \multicolumn{4}{|c|}{ Typically developing students } & \multicolumn{4}{|c|}{ Students with ASD } & \multicolumn{4}{|c|}{$\begin{array}{l}\text { Students with motor and/or sensory } \\
\text { disabilities }\end{array}$} \\
\hline & $r_{s}$ loneliness & $B$ & $S E$ & $\beta$ & $r_{s}$ loneliness & $B$ & $S E$ & $\beta$ & $r_{s}$ loneliness & $B$ & $S E$ & $\beta$ \\
\hline Constant & & 24.88 & 2.29 & & & 22.40 & 3.58 & & & 19.33 & 2.58 & \\
\hline Gender & -0.06 & -0.49 & 0.90 & -0.05 & 0.14 & $2.82^{\circ}$ & 1.48 & $0.20^{\circ}$ & -0.04 & 0.25 & 1.01 & 0.04 \\
\hline Number of friends & $-0.24^{* * *}$ & $-0.54^{\circ}$ & 0.32 & $-0.14^{\circ}$ & -0.06 & -0.09 & 0.35 & -0.03 & -0.16 & 0.36 & 0.35 & 0.13 \\
\hline Friendship quality & $-0.21^{*}$ & -0.49 & 0.44 & -0.10 & -0.11 & -0.98 & 0.61 & -0.17 & $-0.28^{*}$ & -0.45 & 0.59 & -0.11 \\
\hline Social self-concept, SS & $-0.45^{* * *}$ & $-1.11^{*}$ & 0.42 & $-0.28^{*}$ & $-0.65^{* * *}$ & $-2.41^{* * * *}$ & 0.56 & $-0.66^{* * *}$ & $-0.65^{* * * *}$ & $-1.51^{* *}$ & 0.44 & $-0.49^{* * *}$ \\
\hline Social self-concept, OS & $-0.47^{* * * *}$ & $-1.17^{* *}$ & 0.39 & $-0.32^{* *}$ & $-0.49^{* * * *}$ & 0.12 & 0.52 & 0.04 & $-0.43^{* *}$ & -0.62 & 0.45 & -0.20 \\
\hline
\end{tabular}

Social self-concept, SS = Social self-concept Same Sex, Social Self-Concept, OS = Social self-concept Opposite Sex.

*** Beta coefficient $(\beta)$ significant at $p<.001$.

** $\beta$ significant at $p<.01$.

* $\beta$ significant at $p<.05$.

- $\beta$ significant at $p<.10$.

ns, $\beta$ not significant. 
was compared, with students with ASD as a reference group. The direct $R^{2}=0.70$ and crossed $R^{2}=0.62$ did not differ significantly from each other, according to the Steiger's $Z$-test $(Z=1.55 ; p>.05)$. Also none of the regression weights of the individual predictors in the ASD group differed significantly from the regression weights of the individual predictors in the Motor and/or sensory group.

In a second step, the regression analysis of typically developing students and students with ASD were compared to each other. Comparison of the fit of the model from the Typical group and the ASD group revealed that there was no significant difference between the respective $R^{2}$ values $(Z=0.85, p>.05)$. To test differences in the structure of the models, the Typical group was used as a reference group. The direct $R^{2}=0.61$ and crossed $R^{2}=0.51$ did differ significantly from each other, according to the Steiger's $Z$-test $(Z=2.19 ; p<.05)$. Further analysis revealed that the opposite-sex social self-concept had significantly more effect on loneliness for typically developing students than for students with ASD $(Z=2.00 ; p<.05)$. Gender and same-sex social self-concept had marginally more significant effect on loneliness for students with ASD than for typically developing students (gender: $Z=1.91, p<.10$; same-sex social self-concept: $Z=-1.84, p<.10)$.

In a third step, the regression analysis of typically developing students and students with motor and/or sensory disabilities were compared to each other. Comparison of the fit of the model from the Typical group and the Motor and/or sensory group revealed that there was no significant difference between the respective $R^{2}$ values $(Z=0.17, p>.05)$. To test differences in the structure of the models, the Typical group was used as a reference group. The direct $R^{2}=0.61$ and crossed $R^{2}=0.55$ did not differ significantly from each other, according to the Steiger's $Z$-test $(Z=1.49 ; p>.05)$. Further analysis revealed that only the number of friends had marginally more effect on loneliness rates for typically developing students than for students with motor and/or sensory disabilities $(Z=1.92 ; p<.10)$.

\subsection{Post hoc analyses regarding friendships, social self-concept and loneliness}

To test whether differences in the prediction of loneliness between typically developing students $(N=107)$ and students with SEN (students with ASD: $N=54$; students with motor and/or sensory disabilities: $N=48$ ) were not obscured by the differences in sample sizes and since no significant differences were found in the prediction of loneliness between students with ASD and students with motor and/or sensory disabilities, correlations and regression analyses were also calculated for students with SEN as one group $(N=102)$. Results of the regression analyses were also compared to the results of the typically developing students. Typically developing students and students with SEN did not differ significantly in gender, age, socio-economic status nor ethnicity. However, in order to improve comparability with the previous models, gender was included in the analyses. Results of these post hoc analyses are displayed in Table 3.

Spearman Rho correlations indicated significant links between friendship quality $(p<.01)$, same-sex social self-concept $(p<.001)$ and opposite-sex social self-concept $(p<.001)$ on the one hand and loneliness on the other. However, based on the regression analyses, only same-sex social self-concept had a significant effect on loneliness $\left(R^{2}=0.43, F(5,96)=14.71\right.$, $p<.001)$ for students with SEN. Also friendship quality had a marginally significant effect on loneliness $(p<.10)$. Gender, number of friends and opposite-sex social self-concept did not significantly predict loneliness prevalence for the entire group of students with SEN. Comparison of the fit of the model from the typically developing students and the students with SEN revealed that there was no significant difference between the respective $R^{2}$ values $(Z=0.55, p>.05)$. To test differences in the structure of the models, the Typical group was used as a reference group. The direct $R^{2}=0.61$ and crossed $R^{2}=0.50$ did differ significantly from each other, according to the Steiger's $Z$-test $(Z=2.07 ; p<.05)$. Further analysis revealed that the number of friends and the opposite-sex social self-concept had marginally more effect on loneliness rates for typically developing students than for students with SEN (number of friends: $Z=1.75 ; p<.10$; opposite-sex social self-concept: $Z=1.94 ; p<.10)$. Same-sex social self-concept had marginally more effect on loneliness rates for students with SEN than for typically developing students $(Z=-1.76, p<.10)$.

Table 3

Correlation and multiple regression weights for all groups of students.

\begin{tabular}{|c|c|c|c|c|c|c|c|c|}
\hline & \multicolumn{4}{|c|}{ Typically developing students } & \multicolumn{4}{|c|}{ Students with SEN } \\
\hline & $r_{s}$ loneliness & $B$ & $S E$ & $\beta$ & $r_{s}$ loneliness & $B$ & $S E$ & $\beta$ \\
\hline Constant & & 24.88 & 2.29 & & & 21.92 & 2.02 & \\
\hline Gender & -0.06 & -0.49 & 0.90 & -0.05 & -0.06 & 0.90 & 0.82 & 0.10 \\
\hline Number of friends & $-0.24^{* *}$ & $-0.54^{\circ}$ & 0.32 & $-0.14^{\circ}$ & -0.08 & 0.16 & 0.24 & 0.05 \\
\hline Friendship quality & $-0.21^{*}$ & -0.49 & 0.44 & -0.10 & $-0.26^{* * *}$ & $-0.78^{\circ}$ & 0.40 & $-0.16^{\circ}$ \\
\hline Social self-concept, SS & $-0.45^{* * *}$ & $-1.11^{*}$ & 0.42 & $-0.28^{*}$ & $-0.67^{* * * *}$ & $-2.06^{* * * *}$ & 0.33 & $-0.59^{* * * *}$ \\
\hline Social self-concept, OS & $-0.47^{* * *}$ & $-1.17^{* *}$ & 0.39 & $-0.32^{* * *}$ & $-0.43^{* * * *}$ & -0.18 & 0.33 & -0.05 \\
\hline
\end{tabular}

Social self-concept, SS = Social self-concept Same Sex, Social Self-Concept, OS = Social self-concept Opposite Sex.

*** Beta coefficient $(\beta)$ significant at $p<.001$.

** $\beta$ significant at $p<.01$.

* $\beta$ significant at $p<.05$.

$\beta$ significant at $p<.10$.

ns, $\beta$ not significant. 


\section{Discussion}

At the start of the study, we specified two main goals. The first goal was to examine whether prevalence of loneliness differs among typically developing students, students with ASD and students with motor and/or sensory disabilities at the start of mainstream secondary school. Results of this study revealed that students with ASD felt more often lonely than typically developing students in mainstream 7th grade. This finding confirms most of the previous studies among individuals with ASD (e.g., Bauminger \& Kasari, 2000; Bauminger et al., 2003, 2004; Lasgaard et al., 2010; Locke et al., 2010; Whitehouse et al., 2009) and extends previous research by studying loneliness in a bigger sample of students with ASD in fully inclusive settings in mainstream 7th grade. However, it must be noted that not all fully included students with ASD in 7th grade felt lonely. The majority of the students with ASD did fairly well and did not feel lonely at school, but the proportion of students with ASD that feels lonely was twice as large compared to the proportion of typically developing students that feels lonely. Loneliness prevalence among 7th grade students with motor and/or sensory disabilities was rather low (around $12 \%$ ). Contrary to former findings among hard-of-hearing students (Kent, 2003; Most, 2007), loneliness prevalence among students with motor and/or sensory disabilities in this sample was comparable to the rates among typically developing students. Furthermore, this first comparison in loneliness prevalence between individuals with ASD and students with other types of SEN revealed that students with ASD might be more prone to feelings of loneliness than students with other types of SEN who are fully included at the start of mainstream secondary school. Twice as many students with ASD felt lonely compared students with motor and/or sensory disabilities.

The second goal of this study was to see whether there were relations between number of perceived friends, friendship quality, social self-concept and loneliness for typically developing students, students with ASD, and students with motor and/or sensory disabilities who were fully included in the first grade of secondary school. A related goal was to see whether these relations differed between typically developing students, students with ASD, and students with motor and/or sensory disabilities. Based on the results of this study, we can conclude that, although there were no differences in the fit of the regression analyses, the relations between friendship, social self-concept and loneliness are slightly different among typically developing students, and students with SEN (i.e., students with ASD and students with motor and/or sensory disabilities). Based on the correlations, it seems that there was a stronger connection between the different aspects of friendships (both number and quality aspects) and loneliness among typically developing students than among students with SEN. Nonetheless, this difference in relations was not as large according to the regression analyses. Friendship quality did not play a significant role in the prediction of loneliness for typically developing students, students with ASD and students with motor and/or sensory disabilities, although there was a marginally significant effect of friendship quality on loneliness for the entire group of students with SEN. However, no significant differences between the groups were found in the weights of this predictor. These results partially contradict former findings, in which friendship quality was only predictive of levels of loneliness among typically developing students, and not for students with ASD (Whitehouse et al., 2009). For typically developing students also the number of friends seemed to play a role. The result was marginally short of statistical significance, but no single significant association, not in the correlations, nor in the regression analyses, between the number of friends and loneliness was detected among students with SEN. This difference was confirmed in the direct comparison of the individual regression weights, in which marginal significant differences in the regression weights of number of friends were detected for typically developing students on the one hand, and students with motor and/or sensory disabilities, and the total group of students with SEN on the other. It seems that, unlike for typically developing students, the number of friends is not related to the prevalence of loneliness in students with ASD and students with motor and/or sensory disabilities. This is an important result in light of the findings that a higher proportion of the students with SEN in mainstream schools than their typically developing classmates have maximum one reciprocal friendship (e.g. Frostad \& Pijl, 2007). It seems if the lower number of friends of students with SEN does not have an effect on their feelings of loneliness, while friendship quality does have a small effect.

Another remarkable finding is the different association between social self-concept and loneliness. While among typically developing students, both same-sex and opposite-sex social self-concept play a significant role in the prediction of loneliness, only same-sex self-concept is significantly associated with loneliness for students with ASD and students with motor and/or sensory disabilities. According to our results, opposite-sex social self-concept is not related to feelings of loneliness for these students. This difference of the effect of social self-concept on loneliness was confirmed in the direct comparison of the individual regression weights, in which same-sex social self-concept seemed to be less important, but opposite-sex social self-concept seemed to be more important in the prediction of loneliness for typically developing students on the one hand and students with SEN on the other hand. From a developmental perspective, the association between opposite-sex social self-concept and feelings of loneliness is to be expected. For the majority of typically developing students, the interest in the opposite sex increases during this time, resulting in a shift from same-sex cliques to mixed-sex cliques and the occurrence of the first romantic relationships (e.g., Rubin et al., 2006). Nonetheless, based on our findings, it seems as if the development of students with motor and/or sensory disabilities and students with ASD as a group may be facing a developmental delay concerning this particular evolution. However, so far, no data underpinning this hypothesis are available.

A final remark concerns gender differences in loneliness prevalence. Although gender did not seem to have an influence on the loneliness prevalence for most students, we did find a small indication for gender differences in the ASD group, in which girls with ASD reported slightly higher levels of loneliness than boys with ASD $(p<.10)$. This finding is even more 
remarkable since there were only six girls with ASD in the group, compared to 52 boys with ASD. Consequently, one might expect more significant differences between boys and girls with ASD in larger samples. However, this finding cannot be compared to previous results since this study is, to our knowledge, the first one to study gender differences in the loneliness prevalence of students with ASD. Consequently, confirmation of this finding in larger samples is still needed.

In sum, this study provided a more detailed picture on the prevalence and loneliness feelings among typically developing students, students with ASD and students with motor and/or sensory disabilities in mainstream 7th grade. However, some limitations and considerations for further research can be pointed out. First of all, the smaller numbers of students with ASD and students with motor and/or sensory disabilities compared to the typically developing students might have concealed some relations between aspects of friendship, social self-concept and loneliness. However, when analyses were repeated for all students with SEN (i.e., students with ASD and students with motor and/or sensory disabilities together), no remarkable differences emerged in our findings. Nonetheless, the number of students included within this study was relatively small. Consequently, relations had to be fairly strong in order to generate significant results, and smaller relations with loneliness might have remained undetected. Secondly, although regression analyses were performed which inherently assumes causality, no definite conclusions on the direction of the effects can be made. Therefore, longitudinal research, assessing both the stability of all variables and the direction of effects of the associated variables, is recommended to unravel the relations among loneliness and their associated variables. As students become older, other friendship aspects might also have a larger effect on feelings of loneliness. For example, from a developmental perspective, friendships become more intimate as students age (e.g., Rubin et al., 2006), which might also be reflected in its association with feelings of loneliness as students grow older. Furthermore, it would also be interesting to see whether this different association between opposite-sex social self-concept and loneliness among students with SEN continues throughout the years.

Despite these limitations, this study has strengths and practical relevance as well. Results pointed out that especially students with ASD are at risk for loneliness at the start of mainstream secondary education, even in comparison with students with motor/and or sensory disabilities. These findings underline the need to monitor the social situation and subjective feelings of students with ASD more closely. Some of these students are in need of interventions. Although more information is still needed to set up these interventions, the results of this study are a first step in unraveling the complex interrelations between aspects of social participation and loneliness. Based on this study, it is suggested that, as the relations between aspects of social participation and loneliness are different for students with SEN and typically developing students at this age, students with SEN at this age are in need of different or adapted types of interventions, with more focus on enhancing same-sex social self-concept and, to a lesser extent, friendship quality.

\section{References}

Avramidis, E. (2010). Social relationships of pupils with special educational needs in the mainstream primary class: Peer group membership and peer-assessed social behaviour. European Journal of Special Needs Education, 25, 413-429. http://dx.doi.org/10.1080/08856257.2010.513550.

Baird, G., Simonoff, E., Pickles, A., Chandler, S., Loucas, T., Meldrum, D., et al. (2006). Prevalence of disorders of the autism spectrum in a population cohort of children in South Thames: The Special Needs and Autism Project (SNAP). The Lancet, 368, 210-215. http://dx.doi.org/10.1016/S0140-6736(06)69041-7.

Bauminger, N., \& Kasari, C. (2000). Loneliness and friendship in high-functioning children with autism. Child Development, 71, 447-456. http://dx.doi.org/ $10.1111 / 1467-8624.00156$.

Bauminger, N., Shulman, C., \& Agam, G. (2003). Peer interaction and loneliness in high-functioning children with autism. Journal of Autism and Developmental Disorders, 33, 489-507. http://dx.doi.org/10.1023/A:1025827427901.

Bauminger, N., Shulman, C., \& Agam, G. (2004). The link between perception of the self and of social relationships in high functioning children with autism. Journal of Developmental and Physical Disabilities, 16, 193-213. http://dx.doi.org/10.1023/B:JODD.0000026616.24896.c8.

Brown, B. B., \& Klute, C. (2003). Friendships, cliques, and crowds. In G. R. Adams \& M. D. Berzonsky (Eds.), Blackwell handbook of adolescence (pp. 330-348). Malden, MA: Blackwell.

Cassidy, J., \& Asher, S. R. (1992). Loneliness and peer relations in young children. Child Development, 63, 350-365. http://dx.doi.org/10.2307/1131484.

Chamberlain, B., Kasari, C., \& Rotherham-Fuller, E. (2007). Involvement or isolation? The social networks of children with autism in regular classrooms. Journal of Autism and Developmental Disorders, 37, 230-242. http://dx.doi.org/10.1007/s10803-006-0164-4.

Chambers, S. M., \& Kay, R. W. (1992). Research on social integration: What are the problems? International Journal of Disability, Development and Education, 39, 4759. http://dx.doi.org/10.1080/0156655920390106.

De Ro, J. (Ed.). (2008). Education in Flanders. The Flemish educational landscape in a nutshell [Brochure] Brussels, Belgium: Agency for Educational Communication. Retrieved from http://www.ond.vlaanderen.be/publicaties/?nr=120.

De Vellis, R. F. (2003). Scale development: Theory and applications (2nd ed.). Thousand Oaks, CA: Sage.

Field, A. (2009). Discovering statistics using SPSS (3rd ed.). Thousand Oaks, CA: Sage.

Frostad, P., \& Pijl, S. J. (2007). Does being friendly help in making friends? The relation between the social position and social skills of pupils with special needs in mainstream schools. European Journal of Special Needs Education, 22, 15-30. http://dx.doi.org/10.1080/08856250601082224

Galanaki, E., \& Vassilopoulou, H. D. (2007). Teachers and children's loneliness: A review of the literature and educational implications. European Journal of Special Needs Education, 22, 455-475. http://dx.doi.org/10.1007/BF03173466.

Garbin, C. P. (2012). Comparing a multiple regression model across groups. Retrieved from http://psych.unl.edu/psycrs/statpage/rhtest_eg2a.pdf

Goossens, L., Lasgaard, M., Luyckx, K., Vanhalst, J., Mathias, S., \& Masy, E. (2009). Loneliness and solitude in adolescence: A confirmatory factor analysis of alternative models. Personality and Individual Differences, 47, 890-894. http://dx.doi.org/10.1016/j.paid.2009.07.011.

Hardy, C. L., Bukowski, W. M., \& Sippola, L. K. (2002). Stability and change in peer relationships during the transition to middle level school. Journal of Early Adolescence, 22, 117-142. http://dx.doi.org/10.1177/0272431602022002001.

Heinrich, L. M., \& Gullone, E. (2006). The clinical significance of loneliness: A literature review. Clinical Psychology Review, 26, 695-718. http://dx.doi.org/10.1016/ j.cpr.2006.04.002.

Hu, L., \& Bentler, P. M. (1999). Cutoff criteria for fit indexes in covariance structure analysis: Conventional criteria versus new alternatives. Structural Equation Modeling, 6, 1-55. http://dx.doi.org/10.1080/10705519909540118.

Humphrey, N., \& Ainscow, M. (2006). Transition club: Facilitating learning, participation and psychological adjustment during the transition to secondary school. European Journal of Psychology of Education, 21, 319-331. http://dx.doi.org/10.1007/BF03173419.

Huurre, T. M., \& Aro, H. M. (1998). Psychosocial development among adolescents with visual impairment. European Child E Adolescent Psychiatry, 7, 73-78. http:// dx.doi.org/10.1007/s007870050050. 
Kanner, L. (1943). Autistic disturbances of affective contact. Nervous Child, 2, 217-250, Retrieved from http://www.neurodiversity.com/library_kanner_ 1943.html.

Kent, B. A. (2003). Identity issues for hard-of-hearing adolescents aged 11, 13, and 15 in mainstream settings. Journal of Deaf Studies and Deaf Education, 8, 315324. http://dx.doi.org/10.1093/deafed/eng017.

Lasgaard, M., Nielsen, A., Eriksen, M. E., \& Goossens, L. (2010). Loneliness and social support in adolescent boys with autism spectrum disorders. Journal of Autism and Developmental Disorders, 40, 218-226. http://dx.doi.org/10.1007/s10803-009-0851-z.

Locke, J., Ishijima, E. H., Kasari, C., \& London, N. (2010). Loneliness, friendship quality and the social networks of adolescents in high-functioning autism in an inclusive school setting. Journal of Research in Special Educational Needs, 10, 74-81. http://dx.doi.org/10.1111/j.1471-3802.2010.01148.x.

Malcolm, K. T., Jensen-Campbell, L. A., Rex-Lear, M., \& Waldrip, A. M. (2006). Divided we fall: Children's friendships and peer victimization. Journal of Social and Personal Relationships, 23, 721-740. http://dx.doi.org/10.1177/0265407506068260.

Marcoen, A., \& Goossens, L. (1990). De Leuvense Eenzaamheidsschaal voor Kinderen en Adolescenten (LEKA) [The Loneliness and Aloneness Scale for Children and Adolescents (LACA)]. Nederlands Tijdschrift voor de Psychologie, 45, 289-292.

Marcoen, A., Goossens, L., \& Caes, P. (1987). Loneliness in pre-though late adolescence: Exploring the contributions of a multidimensional approach. Journal of Youth and Adolescence, 16, 561-576. http://dx.doi.org/10.1007/BF02138821.

Margalit, M. (1994). Loneliness among children with special needs. New York: Springer-Verlag.

Marsh, H. W., Ellis, L. A., Parada, R. H., Richards, G., \& Heubeck, B. G. (2005). A short version of the Self Description Questionnaire II: Operationalizing criteria for short-form evaluation with new applications of confirmatory factor analyses. Psychological Assessment, 17, 81-102. http://dx.doi.org/10.1037/10403590.17.1.81.

Meijer, C. J. W. (Ed.). (2003). Special education across Europe in 2003: Trends in provision in 18 European countries. Middelfart, Denmark: European Agency for Development in Special Needs Education. Retrieved from http://www.european-agency.org/publications/ereports/special-education-across-europe-in2003/special_education_europe.pdf.

Meng, Rosenthal, \& Rubin, (1992). Comparing correlated correlation coefficients. Psychological Bulletin, 111, 172-175. http://dx.doi.org/10.1037/00332909.111.1.172.

Most, T. (2007). Speech intelligibility, loneliness, and sense of coherence among deaf and hard-of-hearing children in individual inclusion and group inclusion. Journal of Deaf Studies and Deaf Education, 12, 495-503. http://dx.doi.org/10.1093/deafed/enm015.

Paternoster, R., Brame, R., Mazarolle, P., \& Piquero, A. (1998). Using the correct statistical test for the equality of regression coefficients. Criminology, $36,859-866$. http://dx.doi.org/10.1111/j. 1745-9125.1998.tb01268.x

Peplau, L. A., \& Perlman, D. (1982). Perspectives on loneliness. In L. A. Peplau \& D. Perlman (Eds.), Loneliness: A sourcebook of current theory, research and therapy (pp. 1-18). New York: Wiley.

Perlman, D., \& Landolt, M. A. (1999). Examination of loneliness in children-adolescents and in adults: Two solitudes or a unified enterprise? In K. J. Rotenberg \& S. Hymel (Eds.), Loneliness in childhood and adolescence (pp. 325-347). Cambridge, England: Cambridge University Press.

Pijl, S. J., \& Frostad, P. (2010). Peer acceptance and self-concept of students with disabilities in regular education. European Journal of Special Needs Education, 25, 93-105. http://dx.doi.org/10.1080/08856250903450947.

Pijl, S. J., Frostad, P., \& Flem, A. (2008). The social position of pupils with special needs in regular schools. Scandinavian Journal of Educational Research, 52, $387-405$. http://dx.doi.org/10.1080/00313830802184558.

Pijl, S. J., Skaalvik, E. M., \& Skaalvik, S. (2010). Students with special needs and the composition of their peer group. Irish Educational Studies, 29, 57-70. http:// dx.doi.org/10.1080/03323310903522693

Reversi, S., Langher, V., Crisafulli, V., \& Ferri, R. (2007). The quality of disabled students' school integration. A research experience in the Italian state school system. School Psychology International, 28, 403-418. http://dx.doi.org/10.1177/0143034307084132.

Romitti, P., Puzhankara, S., Mathews, K., Zamba, G., Cunniff, C., Andrews, J., et al. (2009). Prevalence of Duchenne/Becker Muscular Dystrophy among males aged 5-24 years - Four states, 2007. Morbidity \& Mortality Weekly Report, 58, 1119-1122, Retrieved from http://www.cdc.gov/mmwr/preview/mmwrhtml/ mm5840a1.htm.

Rubin, K. H., Bukowski, W., \& Parker, J. G. (2006). Peer interactions, relationships and groups. In N. Eisenberg (Ed.), Social, emotional and personal development (6th ed., pp. 571-645). Wiley: John Wiley \& Sons Inc.

Simons, J., \& Vangenechten, L. (2002). Toepassing van de Self-Description Questionnaire II voor het nagaan van self-esteem op Vlaamse jongeren van 16 en 17 jaar [Application of the Self-Description Questionnaire II to assess self-esteem in Flemish youngsters of 16 and 17 years old]. In J. Simons (Ed.), Actuele themata uit de psychomotorische therapie, Jaarboek 2002 (pp. 125-151). Leuven: Acco.

Symes, W., \& Humphrey, N. (2011). The deployment, training and teacher relationships of teaching assistants supporting pupils with autistic spectrum disorders (ASD) in mainstream secondary schools. British Journal of Special Education, 38, 57-64. http://dx.doi.org/10.1111/j.1467-8578.2011.00499.x.

United Nations. (2006). Convention on the rights of persons with disabilities and optional protocol. New York: United Nations. Retrieved from http://www.un.org/esa/ socdev/enable/rights/convtexte.htm.

Volkmar, F. R., Szatmari, P., \& Sparrow, S. S. (1993). Sex differences in pervasive developmental disorders. Journal of Autism and Developmental Disorders, 23, 579591. http://dx.doi.org/10.1007/BF01046103.

Watkins, A. (Ed.). (2010). Special needs education. Country data 2010. Odense, Denmark: European Agency for Development in Special Needs Education. Retrieved from http://www.european-agency.org/publications/ereports/special-needs-education-country-data-2010/SNE-Country-Data-2010.pdf.

Whitehouse, A. J. O., Durkin, K., Jaquet, E., \& Ziatas, K. (2009). Friendship, loneliness and depression in adolescents with Asperger's Syndrome. Journal of Adolescence, 31, 302-322. http://dx.doi.org/10.1016/j.adolescence.2008.03.004. 